\title{
$\beta$-synuclein promotes synaptic vesicle dopamine uptake and rescues dopaminergic neurons from MPTP-induced death
}

\section{Natalia Ninkina}

Cardiff University

Steven J. Millership

Cardiff University

Owen M. Peters

Cardiff University

\section{Natalie Connor-Robson}

Cardiff University

Kirill Chaprov

Institute of Physiologically Active Compounds RAS

\author{
Alex Montoya \\ MRC London Institute of Medical Sciences \\ Holger Kramer \\ MRC London Institute of Medical Sciences \\ Dominic J. Withers \\ Imperial College London \\ Vladimir Buchman ( $\square$ buchmanvl@cf.ac.uk) \\ Cardiff University https://orcid.org/0000-0002-7631-8352
}

\section{Research article}

Keywords: Dopamine, dopaminergic neurons, dopaminergic synapses, synaptic vesicles, neurotransmitter vesicular uptake, MPTP toxicity, synucleins, Parkinson's disease

Posted Date: August 24th, 2020

DOI: https://doi.org/10.21203/rs.3.rs-61790/v1

License: (c) (1) This work is licensed under a Creative Commons Attribution 4.0 International License.

Read Full License 


\section{Abstract \\ Background.}

Previous studies demonstrated that dopaminergic neurons in the substantia nigra pars compacta (SNpc) of mice with null mutations for genes encoding a-synuclein and/or $\mathrm{y}$-synuclein are resistant to 1-methyl-4phenyl-1,2,3,6-tetrahydropyridine (MPTP) toxicity. An original straightforward interpretation of these results was that these proteins are directly involved in the mechanism of MPTP-induced degeneration and this view has become commonly accepted. Here we provide evidence that a plausible alternative explanation of this resistance is not the absence of these synucleins per se but their substitution on the membrane of synaptic vesicles by the third member of the family, $\beta$-synuclein.

\section{Methods.}

An effect of sub-chronic MPTP regimen on dopaminergic neurons of SNpc was studied in mice lacking members of the synuclein family in all possible combinations. Dopamine uptake was assessed in synaptic vesicles isolated from synuclein null mutant mice. Protein composition of synaptic vesicles was studied by mass spectrometry.

\section{Results.}

Dopaminergic neurons of mice lacking $\beta$-synuclein singularly or in combination with the loss of other synucleins, were sensitive to the toxic effect of MPTP. Dopamine uptake by synaptic vesicles isolated from the striatum of triple $\alpha / \beta / \gamma$-synuclein deficient mice was significantly reduced, while reintroduction of $\beta$-synuclein either in vivo or in vitro reversed this effect. Proteomic analysis of complexes formed on the surface of synuclein-free synaptic vesicles after addition of recombinant $\beta$-synuclein identified multiple integral constituents of these vesicles as well as typically cytosolic proteins, including key enzymes involved in dopamine synthesis, tyrosine hydroxylase $(\mathrm{TH})$ and aromatic L-amino acid decarboxylase (AADC).

\section{Conclusions.}

Of the three members of the synuclein family, only $\beta$-synuclein can play a scaffolding role for the assembly of molecular complexes that potentiate the ability of synaptic vesicles to uptake and sequester dopamine and other structurally similar molecules, including 1-methyl-4-phenylpyridinium (MPP ${ }^{+}$), a toxic metabolite of MPTP. The increased presence and activity of $\beta$-synuclein at the synaptic vesicles, and not the absence of other synucleins per se, explains the decreased sensitivity to MPTP toxicity of SNpc dopaminergic neurons in mice lacking a-synuclein and/or $y$-synuclein. 


\section{Background}

Three members of the synuclein family, $a$-, $\beta$ - and $y$-synuclein, are involved in various important molecular processes in presynaptic terminals. Gain-of-toxic-function is believed to be the main mechanism of the involvement of these proteins, a-synuclein in particular, in pathogenesis of Parkinson's disease and certain other neurodegenerative diseases collectively known as synucleinopathies, but the loss-offunction can also be a factor contributing to synaptic dysfunction associated with these diseases [1-5]. However, null mutations inactivating one or even two synuclein-encoding genes have limited effects on mouse physiology. The most notable consequence of a-synuclein, $\gamma$-synuclein or double $a / \gamma$-synuclein null mutations for nigrostriatal system function is a partial [6-9] or even complete [6, 9-12] resistance of dopaminergic neurons of the SNpc to various regimens of the Parkinsonian mimetic toxin MPTP. These observations have led to the hypothesis that these two synucleins are directly involved in, and required for, the MPTP-induced degeneration of dopaminergic neurons in the SNpc.

This straightforward assumption, nevertheless, does not take into consideration a possibility that the third member of the family, $\beta$-synuclein, may play a role in the resistance of SNpc neurons to MPTP toxicity. $\beta$-synuclein is highly expressed in the same neurons as $\alpha$-synuclein, including dopaminergic neurons of the SNpc, and co-localises with a-synuclein in their presynaptic terminals [13-15]. Together with the high similarity between amino acid sequences of synucleins, this suggests that when a family member is absent, it can be replaced by another one. This can partially compensate for the lost function but also can bring certain "added values", i.e. functional changes that manifest only when normal synaptic physiology is challenged. Indeed, increased expression of $\beta$-synuclein was observed in the midbrain of both $\alpha$-synuclein and $\alpha / \gamma$-synuclein null mutant mice and restoration of a-synuclein expression reversed this effect $[9,12]$. In several experimental in vivo systems, expression of $\beta$-synuclein ameliorated neuronal pathology caused by overexpression of a-synuclein [16-21]. General neuroprotective abilities of $\beta$-synuclein have been attributed to inhibition of pro-apoptotic and activation of pro-survival signaling pathways but through unknown mechanisms $[9,16]$.

Here we demonstrate that $\beta$-synuclein plays a pivotal role in developing resistance to MPTP toxicity by SNpc dopaminergic neurons lacking the normal balance of synucleins. This might be due, at least in part, to improved sequestering of MPP + into synaptic vesicles, which is concordant with an observed ability of $\beta$-synuclein to potentiate dopamine uptake by striatal synaptic vesicles.

\section{Methods}

Generation of experimental animals. Generation of a-synuclein KO (from original mouse line described in [22]), $\beta$-synuclein KO (from original mouse line described in [23]), $\gamma$-synuclein $K O$ [24], and a/ $Y$-synuclein double KO mice on C57BI6J (Charles River) background was described previously [12, 25]. Homozygous $\mathrm{a} / \mathrm{\gamma}$-synuclein double $\mathrm{KO}$ and $\beta$-synuclein $\mathrm{KO}$ mice were crossed to generate triple heterozygous mice. Intercrossing of these mice produced founders of TKO, double KO, single KO and wild type colonies used in this study. Therefore, founders of all these colonies were either first-, or second-generation siblings and 
all experimental animals were on the same $\mathrm{C} 57 \mathrm{BI} 6 \mathrm{~J}$ genetic background. Mouse genotyping was carried out as described previously $[12,23,24]$. Unless otherwise stated, $4-5$ months old male mice were used in all experiments. Neuron counts were performed by investigators blinded with respect to the sample genotype and treatment. All animal work was carried out in accordance with the United Kingdom Animals (Scientific Procedures) Act (1986).

Subchronic MPTP treatment, immunohistochemistry and neuronal cell counts. Four-month old male mice were injected i.p. once a day for 5 consecutive days with $30 \mathrm{mg} / \mathrm{kg}$ of MPTP (Sigma). 21 days after the last MPTP injection animals were euthanized by phenobarbital overdose and brains were dissected. Fixation, processing, embedding, preparing of microtome sections and their immunostaining with antibody against TH (mouse monoclonal, clone TH-2 from Sigma, diluted 1:1000) were performed as in our previous studies $[12,24]$. Stereological counting of neurons was carried out as previously described for single and double synuclein $\mathrm{KO}$ mice $[26,27]$.

Immunoblotting. SDS gel electrophoresis and Western blotting were performed as described in our previous publications $[28,29]$. Primary antibodies against AADC (rabbit polyclonal, Synaptic Systems, 1:1000), TH mouse monoclonal, clone 2, (mouse monoclonal, clone TH-2, Sigma, 1:5000), synaptophysin (mouse monoclonal, clone 2, BD Transduction Laboratories, 1:25000), synapsin Ila (mouse monoclonal, clone 1, BD Transduction Laboratories, 1:5000), VAMP2 (mouse monoclonal, clone 69.1, Synaptic Systems, 1:1000), VMAT-2 (rabbit polyclonal, Sigma, 1:1000), a-synuclein (mouse monoclonal, clone 42, BD Transduction Laboratories, 1:500), $\beta$-synuclein (mouse monoclonal, clone 8, BD Transduction Laboratories, 1:5000) and $y$-synuclein (rabbit polyclonal, SK23 [24], 1:1000), secondary HRP-conjugated anti-mouse or anti-rabbit antibodies (GE Healthcare, 1:3000) and ECL + system (GE Healthcare) were used for detection of target proteins.

Recombinant $\beta$-synuclein. Expression of $\beta$-synuclein in E.coli and purification of the recombinant protein were performed as described previously [30]. For CLIP experiments a fragment encoding SAWSHPQFEK sequence tag was cloned in frame with the $\beta$-synuclein ORF in the pRK172 expression vector and the same expression and purification protocols were used to produce $\beta$-synuclein with C-terminal Strep-tag.

Preparation of synaptosomal and synaptic vesicle fractions. All procedures were carried out at $4^{\circ} \mathrm{C}$. Dorsal striata dissected from 6 mice were homogenised in $1 \mathrm{ml}$ of the $0.32 \mathrm{M}$ sucrose; $5 \mathrm{mM}$ HEPES, $\mathrm{pH}$ 7.4 with protease inhibitors (Complete Mini from Roche) using a glass homogenizer (if more striata were used all volumes were scaled up accordingly). Nuclei and cell debris were sedimented by centrifugation at $1,000 \times \mathrm{g}$ for $10 \mathrm{~min}$ and the supernatant (S1) was further centrifuged at $20,000 \times \mathrm{g}$ for $20 \mathrm{~min}$ to obtain cytosolic (S2, supernatant) and crude synaptosomes (P2, pellet) fractions. For synaptosomal dopamine uptake assay, the $\mathrm{P} 2$ pellet was resuspended by vortexing in $0.5 \mathrm{ml}$ of synaptosomal uptake assay buffer (10 mM HEPES, pH 7.4; $5.6 \mathrm{mM}$ glucose; $120 \mathrm{mM} \mathrm{NaCl} ; 5 \mathrm{mM} \mathrm{KCl} ; 1.2 \mathrm{mM} \mathrm{CaCl}_{2} ; 1.2 \mathrm{mM}$ $\mathrm{MgCl}_{2} ; 1 \mathrm{mM}$ ascorbic acid; $10 \mu \mathrm{M}$ pargyline). For isolation of synaptic vesicles, the $\mathrm{P} 2$ pellet was resuspended by vortexing in $0.5 \mathrm{ml}$ of the $0.32 \mathrm{M}$ sucrose, diluted with $2 \mathrm{ml}$ of deionised $\mathrm{H}_{2} \mathrm{O}$, homogenised in a glass/teflon homogeniser and left on ice for $10 \mathrm{~min}$ before adding $0.3 \mathrm{ml}$ of $250 \mathrm{mM}$ 
HEPES, pH 7.4 and $0.3 \mathrm{ml}$ of $1 \mathrm{M}$ potassium tartrate. Synaptic membranes (P3) were separated by centrifugation at $20,000 \times \mathrm{g}$ for $20 \mathrm{~min}$ and the supernatant (S3) was centrifuged at $120,000 \times \mathrm{g}$ for $40 \mathrm{~min}$ to obtain the synaptic vesicle pellet (P4) that was resuspended in $1 \mathrm{ml}$ of vesicular uptake assay buffer (25 mM HEPES, pH 7.4; 100 mM potassium tartrate; 0.1 mM EDTA; 0.05 mM EGTA; 1.7 mM ascorbic acid; 2 mM ATP) using a syringe fitted with the 25 gauge needle.

\section{Cross-linking with recombinant $\beta$-synuclein, immunoprecipitation and mass spectrometry}

Synaptic vesicle containing synaptosomal fraction (S3) prepared as above from 80 TKO striata, was divided into two equal aliquots and incubated with or without $50 \mu \mathrm{g}$ recombinant Strep-tagged $\beta$ synuclein for $5 \mathrm{~min}$ at $30^{\circ} \mathrm{C}$. DTSSP (Pierce Biotechnology) was added to both samples to the final concentration of $5 \mathrm{mM}$. After 25 min of incubation at $30^{\circ} \mathrm{C}$, crosslinking was terminated by the addition of Tris- $\mathrm{HCl} \mathrm{pH} 7.5$ to $50 \mathrm{mM}$ and synaptic vesicles were spun down by centrifugation at $120000 \times \mathrm{g}$ for $40 \mathrm{~min}$ at $2^{\circ} \mathrm{C}$. Pellets were washed twice with $50 \mathrm{mM}$ tris/ $\mathrm{HCl} \mathrm{pH} \mathrm{7.7;} 150 \mathrm{mM} \mathrm{NaCl}$. Synaptic vesicle membranes were lysed in solubilisation buffer (50 mM Tris-HCl pH 7.5, $150 \mathrm{mM} \mathrm{NaCl}, 1 \%$ Triton X-100 with Roche Complete Mini protease inhibitors) and lysates were incubated with $200 \mu$ l of a $50 \%$ suspension of Tactin beads (iba GmbH lifesciences) in solubilisation buffer for $25 \mathrm{~min}$ at $4^{\circ} \mathrm{C}$. Beads were washed four times with solubilisation buffer, and cross-linked proteins were eluted from $\beta$-synuclein (that remained attached to beads via its Strep-tag) by incubation of beads with $50 \mu \mathrm{l}$ of $25 \mathrm{mM} \mathrm{Tris/Cl} \mathrm{pH}$ 7.5; $50 \mathrm{mM} \mathrm{DTT}$ for $40 \mathrm{~min}$ at $37^{\circ} \mathrm{C}$ with occasional mixing. Total protein content in two samples was normalised using a Quick Start Bradford protein assay (Bio-Rad). Proteins were processed for LC-MS analysis by in-solution digestion with reduction and alkylation using $10 \mathrm{mM}$ DTT and $25 \mathrm{mM}$ iodoacetamide respectively, followed by overnight trypsinisation (Promega). Post-digestion, samples were acidified with trifluoroacetic acid, de-salted using reversed-phase spin tips (Glygen Corp.) and dried using a vacuum centrifuge. Dried peptides were solubilised in trifluoroacetic acid and analysed in technical duplicates with separation using an Ultimate 3000 UHPLC system by loading onto a trap column (Acclaim Pepmap 100, $100 \mu \mathrm{m} \times 2 \mathrm{~cm}, \mathrm{C} 18$ ) at $8 \mu \mathrm{L} / \mathrm{min}$ in $2 \%$ acetonitrile, $0.1 \%$ trifluoroacetic. Peptides were then eluted on-line to an analytical column (Acclaim Pepmap RSLC, $75 \mu \mathrm{m} \times 50 \mathrm{~cm}, \mathrm{C18}$ ) and separated using a 120 min gradient. Eluted peptides were analysed by an LTQ Velos Orbitrap mass spectrometer as described previously [31] and Maxquant v1.5.3.8 software was used to align all raw data files. Variable modifications of oxidation (methionine), acetylation (protein N-terminal) and CAM thiopropanoyl (lysine and protein N-terminal) were permitted. The reduced DTSSP crosslinker gives a + 145.01975 Da addition to potential amine-reactive sites. Fixed modification of carbamidomethylation (cysteines) and up to 4 missed cleavages were permitted. Label-free quantitation (LFQ), 're-quantify', 'match between runs' and 'iBAQ' options were all selected. Raw data were searched against the UniprotKB Mus musculus database (downloaded November 2015 containing 79,900 protein sequences) and results were filtered to a $1 \%$ false discovery rate. Proteins were filtered for those containing at least two unique peptides and with undetectable abundance in control pulldowns. 
Synaptic vesicle dopamine uptake. Protein concentration in the synaptic vesicle fraction was measured using Quick Start Bradford protein assay (Bio-Rad). For each uptake reaction $100 \mu \mathrm{l}$ of this suspension was mixed in a glass tube with $125 \mu$ of vesicular uptake assay buffer and preincubated at $30^{\circ} \mathrm{C}$ for $15 \mathrm{~min}$. The uptake was initiated by adding $25 \mu \mathrm{l}$ of $0.1 \mu \mathrm{M}{ }^{3} \mathrm{H}$-dopamine $(34.6 \mathrm{Ci} / \mathrm{mmol}$, Perkin Elmer) in the same buffer and after incubation at $30^{\circ} \mathrm{C}$ for $5 \mathrm{~min}$ terminated with $3 \mathrm{ml}$ of ice-cold wash buffer (vesicular uptake assay buffer without ascorbic acid and ATP). To determine non-specific adsorption, control tubes were incubated on ice. To assess VMAT-2-independent uptake, control reactions were performed at $30^{\circ} \mathrm{C}$ in the presence of $10 \mu \mathrm{M}$ tetrabenazine. The level of tetrabenazine-resistant uptake was similar to background levels of uptake at $4^{\circ} \mathrm{C}$ and are therefore not shown. Reaction mixtures were filtered through GF/F filters. After 3 washes with the wash buffer, filters were air dried, placed in vials with SafeScint fluid and radioactivity measured using a Beckman LS6000 Scintillation Counter. For uptake kinetic studies, increasing amounts of cold dopamine $(0-10 \mu \mathrm{M})$ was added to the reactions. Obtained data were used to calculate Vmax and $\mathrm{Km}$ by nonlinear regression method (GraphPad Prism 4.0, GraphPad Software).

Synaptosomal dopamine uptake. Protein concentration in the crude synaptosome fraction was measured using Quick Start Bradford protein assay (Bio-Rad) and concentration of samples was adjusted to $2 \mathrm{mg}$ protein per ml. For each reaction, $25 \mu \mathrm{l}$ of this suspension was mixed in a glass tube with $200 \mu \mathrm{l}$ of synaptosomal uptake assay buffer and preincubated at $30^{\circ} \mathrm{C}$ for $15 \mathrm{~min}$. The uptake was initiated by adding $25 \mu \mathrm{l}$ of $9.8 \mu \mathrm{M}$ dopamine/ $0.2 \mu \mathrm{M}{ }^{3} \mathrm{H}$-dopamine mixture in the same buffer and after $10 \mathrm{~min}$ incubation at $30^{\circ} \mathrm{C}$ terminated with $3 \mathrm{ml}$ of ice-cold wash buffer (synaptosomal uptake assay buffer without ascorbic acid and pargyline). To determine non-specific adsorption, control tubes were incubated on ice. To assess DAT-independent uptake, parallel reactions were performed at $30^{\circ} \mathrm{C}$ in the presence of $10 \mu \mathrm{M}$ nomifensine. The level of nomifensine-resistant uptake was similar to background levels of uptake at $4^{\circ} \mathrm{C}$ and are therefore not shown. Reaction mixtures were filtered through GF/F filters. After 3 washes with the wash buffer, filters were air dried, placed in vials with SafeScint fluid and radioactivity measured using a Beckman LS6000 Scintillation Counter.

\section{Stereotaxic delivery of lentivirus expressing $\beta$-synuclein}

A fragment of human $\beta$-synuclein cDNA that included the coding region and the upstream Kozak sequence was cloned into the unique BamHI site of the pCCLsin.CPPT.PGK.eGFP.WPRE Ientiviral expression vector. $9 \times 10^{5}$ virus transducing units were stereotaxicaly injected at a rate of $1.0 \mu \mathrm{l} / \mathrm{min}$ for $90 \mathrm{sec}$ into the substantia nigra ( $\mathrm{AP}=-3.0, \mathrm{ML}=-1.2, \mathrm{DV}=-4.5$, relative to Bregma) of 9-month old male TKO mice. The same amount of control virus particles prepared using "empty" vector DNA were injected into the contralateral substantia nigra. Dorsal striata from the ipsilateral and controlateral hemisphere were dissected 8 weeks after injections and used for comparing vesicular dopamine uptake.

Statistical analysis. All data are presented as means \pm s.e.m. Statistical analysis was performed using GraphPad Prism 8.2.1 (GraphPad Software). 


\section{Results And Discussion}

A widely accepted hypothesis suggests that intrinsic toxicity of a-synuclein and $\mathrm{Y}$-synuclein is a prerequisite for the demise of dopaminergic neurons in the SNpc of MPTP-treated mice. A logical extrapolation of this presumption would be that $S N p c$ neurons of triple $\alpha / \beta / \gamma$-synuclein null mutant (TKO) mice should be at least as resistant to the toxic effect of MPTP as neurons lacking a-synuclein and $\gamma^{-}$ synuclein. However, morphometric analysis of the number of TH-positive neurons in the SNpc of wild type (WT) and TKO mice treated with a subchronic MPTP regimen [10,12], revealed the same degree of neuronal loss for both genotypes (Fig. 1). This result clearly demonstrated that none of the three synucleins are required for MPTP-induced death of dopaminergic neurons in the SNpc and suggests a protecting role of $\beta$-synuclein may in the single and double $\alpha / \gamma$-synuclein knockout scenarios.

The sensitivity of dopaminergic neurons to MPTP depends on the ability of its active toxic metabolite, $\mathrm{MPP}^{+}$, to enter the cell via the dopamine transporter (DAT)- and to avoid being sequestered in synaptic vesicles by a vesicular monoamine transporter (VMAT-2)-driven mechanism [32, 33]. Thus, dopaminergic neurons with a higher DAT/VMAT-2 ratio, such as SNpc neurons, are more sensitive to MPTP than neurons with a lower ratio, for instance ventral tegmental area (VTA) neurons. We have previously demonstrated that the function of DAT in synapses of SNpc neurons is not affected by the absence of synucleins $[25,34]$. This was further confirmed by studies of in vitro dopamine uptake by synaptosomes isolated from the striatum of wild type and TKO mice that revealed no difference in this DAT-dependent uptake between the two animal groups (Additional file 1). These observations suggest that increased sensitivity of midbrain dopaminergic neurons of TKO mice to MPTP may be related to attenuated VMAT2-dependent $\mathrm{MPP}^{+}$uptake by vesicles lacking these proteins. Consistent with the well-documented ability of synucleins to interact with various biological and synthetic membranes, particularly with high curvature vesicles [35-37], we showed that all three family members co-purify with striatal synaptic vesicles despite being predominantly cytosolic proteins in the striatum of wild type mice (Fig. 2a). To check whether vesicle-associated synucleins affect VMAT-2-dependent uptake we compared the ability of synaptic vesicles isolated from the striatum of 5-month old male TKO and wild type mice to take up ${ }^{3} \mathrm{H}$ dopamine. It has previously been shown that the basal level of cytosolic dopamine in dopaminergic neurons is below $0.1 \mu \mathrm{M}$, which is the detection limit of the intracellular patch electrochemistry technique [38]. Therefore, to imitate physiological conditions, uptake was measured with $10 \mathrm{nM}$ dopamine in the reaction mixture. We observed a $38.5 \pm 4.71 \%$ reduction of tetrabenazine-sensitive (i.e. VMAT-2dependent) dopamine uptake by synaptic vesicles isolated from the striatum of 5-month old male TKO mice when compared to synaptic vesicles from wild type mice of the same age and sex (Fig. 2b). A similar difference between genotypes was found in an independent set of experiments with synaptic vesicles isolated from ageing 14 -month old male (39.2 $\pm 1.29 \%$ reduction) or 18-month old female mice $(39.0 \pm 4.79 \%$ reduction), suggesting that the effect is not age- or sex-dependent. Further analysis demonstrated decreased $V \max (9.97$ vs 12.29) and $\mathrm{Km}$ (117.4 vs 196.1) values for this uptake in the absence of synucleins. These changes were not due to a decrease in either the number of synaptic 
vesicles in dopaminergic synapses or levels of VMAT-2 in the striatum of TKO mice [25] and in synaptic vesicles isolated from the striatum of TKO mice (Fig. 2b, inset).

Reduced dopamine uptake efficiency of synuclein-depleted synaptic vesicles and the resultant decrease of the vesicular dopamine pool explains the attenuated response of TKO mice to amphetamine observed in our previous study [25]. Moreover, this functional deficiency should lead to the accumulation of free cytosolic dopamine within the presynaptic terminals because TH activity and dopamine re-uptake by DAT are unaffected in the striatum of TKO mice [25]. The increased striatal DOPAC/dopamine ratio suggests that to prevent toxicity of free cytosolic dopamine, these mice utilise a compensatory increase of dopamine degradation [25].

It is feasible that synucleins differ in their ability to potentiate vesicular uptake of dopamine and other, structurally similar, molecules e.g. MPP ${ }^{+}$. Thus, functional substitution for the loss of a family member(s) by another, more efficacious member might significantly affect both vesicular dopamine uptake and sensitivity of dopaminergic neurons to MPTP toxicity. The resistance of $\alpha / \gamma$-synuclein-deficient ([12] and Fig. 3a), but sensitivity of $\alpha / \beta-, \beta / \gamma$ - and $\alpha / \beta / \gamma$-synuclein-deficient (Figs. 1 and $3 a$ ) neurons to this drug suggest that within the family only $\beta$-synuclein can efficiently potentiate vesicular uptake. In accordance with this assumption, reduced dopamine uptake, similar to the level of uptake by TKO vesicles, was observed for synaptic vesicles isolated from the striatum of $\beta$-synuclein but not $\alpha$-synuclein or $\gamma$-synuclein null mutant mice (Additional file 2). To confirm the pivotal role of $\beta$-synuclein in potentiating the efficiency of vesicular uptake, we first compared the sensitivity of SNpc dopaminergic neurons to subchronic MPTP administration in three groups of $\beta$-synuclein deficient mice and in three groups of mice lacking the other two synucleins singularly or in combination. In single $\beta$-synuclein and both double $\beta / \gamma$-synuclein and $\alpha / \beta$ synuclein null mutant mice these neurons were sensitive to the drug to approximately the same degree as neurons of wild type mice (Fig. 3a). In contrast, this protocol of MPTP administration did not cause loss of dopaminergic neurons in the SNpc of a-synuclein, $\mathrm{Y}$-synuclein and $\mathrm{a} / \mathrm{Y}$-synuclein null mutant mice (Fig. 3a), consistent with previous observations [10, 12].

Next, we attempted to restore $\beta$-synuclein expression in midbrain neurons of TKO mice using in vivo lentiviral delivery of an expression construct. Stereotaxic injection of viral particles into the SNpc region resulted in $\beta$-synuclein expression and its transport via the nigrostriatal tract (Additional file 3 ) to the dorsal striatum where the protein could be detected by Western blotting (Fig. 3b). Vesicular dopamine uptake was significantly higher in vesicles isolated from the ipsilateral than from contralateral striatum (Fig. 3c), suggesting that $\beta$-synuclein potentiates this process. To assess whether $\beta$-synuclein directly affects vesicular dopamine uptake, we performed the uptake reaction by TKO mouse striata-derived vesicles in the presence of purified recombinant $\beta$-synuclein. Preincubation of isolated vesicles (i.e. from $\mathrm{P} 4$ fraction) with the recombinant protein before adding ${ }^{3} \mathrm{H}$-dopamine did not affect the uptake (Fig. 4a). However, when the vesicle-containing S3 supernatant was incubated with recombinant $\beta$-synuclein followed by spinning down synaptic vesicles (i.e. obtaining P4 fraction from $\beta$-synuclein preincubated S3 supernatant) and using them to measure dopamine uptake, a statistically significant increase was observed compared to the uptake by vesicles from a mock-incubated S3 supernatant (Fig. 4b). This 
effect was not observed for recombinant $\alpha$ - or $\gamma$-synuclein, suggesting that the presence of $\beta$-synuclein alongside one or more proteins contained within the $\mathrm{S} 3$ supernatant are required for efficient synaptic vesicle dopamine uptake.

In an attempt to provide an insight into how supplementing with exogenous $\beta$-synuclein improves dopamine uptake by striatal synaptic vesicles from synuclein-free mice, we assessed the proteome of $\beta$ synuclein-bound vesicles by a combination of the crosslink immunoprecipitation (CLIP) and mass spectrometry techniques. Synaptic vesicle-containing S3 supernatant obtained from the striata of TKO mice was preincubated with Strep-tagged human $\beta$-synuclein followed by incubation with a cleavable crosslinking agent (DTSSP) and subsequent high-speed centrifugation to spin down synaptic vesicles (for details see Methods). Synaptic vesicles isolated from the same S3 supernatant sample preincubated without $\beta$-synuclein but similarly crosslinked were used as a non-specific binding control. Membranes of both control and $\beta$-synuclein-bound vesicles were lysed in a non-ionic detergent solution and protein complexes containing $\beta$-synuclein were pulled down using Tactin magnetic beads that have high affinity for Strep-tagged proteins. Proteins incorporated in these complexes were eluted from the beads by breaking crosslinking bonds with dithiothreitol, leaving Strep-tagged $\beta$-synuclein attached to beads. Protein composition of the resulting CLIP proteome was analysed by mass spectrometry (MS). Proteins identified by the presence of at least two unique peptides in the $\beta$-synuclein-CLIP and undetectable in the control CLIP were further filtered using the CRAPome tool (crapome.org) to remove common non-specific proteins often present in MS immunoprecipitation experiments.

Not surprisingly, around half of the 224 proteins included in the final analysis (thereafter, $\beta$-synuclein-CLIP proteome) were proteins with predominant localisation to, or function at, neuronal membranous structures and synaptic vesicles in particular (Fig. 5a). Presynapse (G0:0098793) appeared to be the top Cellular Component with a false discovery rate (FDR) of 3.44e-27. Mechanistically, proteins involved in presynaptic functions were also vastly overrepresented in this $\beta$-synuclein-CLIP proteome. Gene Ontology analysis revealed Synaptic Vesicle Cycle (G0:0099504) and Neurotransmitter Transport (G0:0006836) as the most represented Biological Processes with FDR of 4.91e-12 and 3.35e-11, respectively. Similarly, Synaptic Vesicle Cycle (MMU4721; FDR 4.85e-12) appeared to have the highest representation between KEGG Pathways, as well as Transmission Across Chemical Synapse (MMU112315) and Neurotransmitter Release Cycle (MMU112310) - between Reactome Pathways (FDR 6.88e-12 and 5.71e-12, respectively).

The improved dopamine uptake after addition of exogenous $\beta$-synuclein was observed only when synaptic vesicles were preincubated with $\beta$-synuclein in the presence of cytosolic factors but not after these factors were removed by high-speed centrifugation at the final step of vesicle purification (Fig. 4). A logical interpretation of these data is that upon interaction with the synaptic vesicle membrane via its $\mathrm{N}$ terminal lipid-binding domain, $\beta$-synuclein attracts certain proteins, principally residing in the cytosol of dopaminergic presynaptic terminals, to the outer surface of these vesicles, and that the resulting molecular complexes improve the efficiency of the VMAT-2 transporter. The absence of VMAT-2 itself between proteins included in the $\beta$-synuclein-CLIP proteome provides additional evidence that its direct interaction with $\beta$-synuclein is not a plausible reason for this improved efficiency. 
A number of proteins, which are not intrinsic constituents of synaptic vesicles at any stage of their presynaptic cycle, have been previously detected in brain synaptic vesicle fractions. It has been suggested that some of these proteins can affect vesicular uptake of dopamine, for example by increasing local availability of ATP in the case of glycolytic enzymes [39] or direct modulation of VMAT-2 activity [40-42]. Amongst the various, principally cytosolic, proteins identified in our analysis of the $\beta$ synuclein-CLIP proteome, the most probable candidates for augmentation of synaptic dopamine uptake are TH and AADC (also known as DOPA decarboxylase, DDC). Both proteins were detected in the $\beta$ synuclein-CLIP but not in the control CLIP samples by Western blot, confirming the findings of the MS analysis (Fig. 5b). These proteins are not only involved in presynaptic dopamine production but can also form a transient complex with VMAT-2, which creates spatial coupling of dopamine synthesis and loading into synaptic vesicles $[43,44]$. Although this coupling cannot explain the improved ${ }^{3} \mathrm{H}$-dopamine uptake in the in vitro assay nor improved synaptic vesicle uptake of $\mathrm{MPP}^{+}$in the striatum of MPTPtreated mice, the $\beta$-synuclein-triggered formation of the TH/AADC/VMAT-2 complex might have an allosteric effect on transporter function.

Although the TH/AADC/VMAT-2 complex is the most obvious scenario, a contribution from other proteins interacting with the vesicle-bound $\beta$-synuclein cannot be excluded and it is feasible that improved function of VMAT-2 in the presence of $\beta$-synuclein is the result of a cumulative effect of several multiprotein interactions rather than of any one particular complex. Indeed, our data suggest that $\beta$ synuclein, via interaction with a number of vesicular and cytosolic proteins, can potentiate formation of various molecular complexes on the surface of synaptic vesicles. This is similar to a-synuclein, which is known to interact with a variety of proteins and function as a chaperone or scaffold for the assembly of multiprotein complexes on the surface of synaptic vesicles, implicating a-synuclein in a number of molecular processes at several stages of the synaptic vesicle cycle $[1-3,5,45-47]$. However, these do not include potentiation of vesicular uptake and therefore, a-synuclein, as well as $\gamma$-synuclein, are unable to compensate for the loss of this particular function of $\beta$-synuclein. All three members of the synuclein family can interact with phospholipids at the outer surface of synaptic vesicles via their conserved $\mathrm{N}$ terminal repeat domain, but the number of functional multiprotein complexes each member can form on a given vesicle is limited. It is feasible that in the presence of all three synucleins (i.e. in the synaptic terminals of dopamine neurons of WT animals), this competition for space results in a limited number of $\beta$-synuclein-triggered complexes formed at the vesicle surface. This is not sufficient to potentiate VMAT-2dependent uptake to the level that can efficiently sequester $\mathrm{MPP}^{+}$in synaptic vesicles and thus, prevent its toxic effect. However, in the absence of one or two other family members, $\beta$-synuclein occupies vacant sites on the vesicle surface, triggering the formation of more complexes that efficiently potentiate vesicular uptake of dopamine and $\mathrm{MPP}^{+}$, making dopaminergic neurons more robust to MPTP-induced toxicity.

\section{Conclusions}


Our experimental data provide evidence that of the three members of the synuclein family, only $\beta$ synuclein can potentiate VMAT-2-dependent uptake of dopamine (and structurally similar molecules) by synaptic vesicles. The increased presence and activity of $\beta$-synuclein at the synaptic vesicles, and not the absence of other synucleins per se, explains the decreased sensitivity to MPTP toxicity of SNpc dopaminergic neurons in mice lacking a-synuclein and/or $\mathrm{Y}$-synuclein.

\section{Abbreviations}

\section{SNpc}

substantia nigra pars compacta

\section{MPTP}

1-methyl-4-phenyl-1,2,3,6-tetrahydropyridine

\section{MPP+}

1-methyl-4-phenylpyridinium

$\mathrm{TH}$

tyrosine hydroxylase

AADC

aromatic L-amino acid decarboxylase

TKO

triple $\alpha / \beta / \gamma$-synuclein null mutant mice

WT

wild type mice

DAT

dopamine transporter

VMAT-2

vesicular monoamine transporter 2

VTA

ventral tegmental area

CLIP

crosslink immunoprecipitation

DTSSP

3,3'-Dithiobis(sulfosuccinimidylpropionate)

MS

mass spectrometry

\section{Declarations}

\section{Ethics approval and consent to participate}


Animal studies were carried out in accordance with the United Kingdom Animals (Scientific Procedures) Act (1986).

\section{Consent for publication}

Not applicable

\section{Availability of data and materials}

All data generated or analysed during this study are included in this published article and its supplementary information files or available from the corresponding author on reasonable request.

\section{Competing interests}

Authors declare no competing interests.

\section{Funding}

This work was supported by The Wellcome Trust (Programme Grant 075615/Z/04/z) and Russian Science Foundation (RSF Grant 19-14-00064) to VLB, Russian Foundation for Basic Research (RFBR Grant 18-04-00515 A) to NN, and funding from the Medical Research Council (MC-A654-5QB40) to DJW. SJM was supported by an Imperial College / Wellcome Trust ISSF Springboard Fellowship (PS3619_WREC).

\section{Authors' contributions}

NN and VLB conceived and supervised the study. NN, SJM, OMP, NCR, KC, AM, HK and VLB conducted the experiments. NN, DJW and VLB analysed data. VLB wrote the manuscript with input of all authors. All authors read and approved the final version of the manuscript.

\section{Acknowledgements}

We thank Peter Faull for technical assistance with mass spectrometry experiments.

\section{References}

1. Burre J, Sharma M, Sudhof TC. Cell Biology and Pathophysiology of alpha-Synuclein. Cold Spring Harb Perspect Med. 2018;8(3):a024091.

2. Sulzer D, Edwards RH. The physiological role of alpha-synuclein and its relationship to Parkinson's Disease. J Neurochem. 2019;150:475-86. 
3. Masato A, Plotegher N, Boassa D, Bubacco L. Impaired dopamine metabolism in Parkinson's disease pathogenesis. Mol Neurodegener. 2019;14:35.

4. Bras J, Gibbons E, Guerreiro R. Genetics of synucleins in neurodegenerative diseases. Acta Neuropathol. 2020. doi:10.1007/s00401-020-02202-1.

5. Bras IC, Dominguez-Meijide A, Gerhardt E, Koss D, Lazaro DF, Santos PI, Vasili E, Xylaki M, Outeiro TF. Synucleinopathies: Where we are and where we need to go. J Neurochem. 2020. doi:10.1007/s00401-020-02202-1.

6. Drolet RE, Behrouz B, Lookingland KJ, Goudreau JL. Mice lacking alpha-synuclein have an attenuated loss of striatal dopamine following prolonged chronic MPTP administration. Neurotoxicology. 2004;25:761-9.

7. Klivenyi P, Siwek D, Gardian G, Yang L, Starkov A, Cleren C, Ferrante RJ, Kowall NW, Abeliovich A, Beal MF. Mice lacking alpha-synuclein are resistant to mitochondrial toxins. Neurobiol Dis. 2006;21:5418.

8. Schluter OM, Fornai F, Alessandri MG, Takamori S, Geppert M, Jahn R, Sudhof TC. Role of alphasynuclein in 1-methyl-4-phenyl-1,2,3,6-tetrahydropyridine-induced parkinsonism in mice. Neuroscience. 2003;118:985-1002.

9. Thomas B, Mandir AS, West N, Liu Y, Andrabi SA, Stirling W, Dawson VL, Dawson TM, Lee MK. Resistance to MPTP-neurotoxicity in alpha-synuclein knockout mice is complemented by human alpha-synuclein and associated with increased beta-synuclein and Akt activation. PLoS One. 2011;6:e16706.

10. Dauer W, Kholodilov N, Vila M, Trillat AC, Goodchild R, Larsen KE, Staal R, Tieu K, Schmitz Y, Yuan CA, et al. Resistance of alpha -synuclein null mice to the parkinsonian neurotoxin MPTP. Proc Natl Acad Sci U S A. 2002;99:14524-9.

11. Fornai F, Schluter OM, Lenzi P, Gesi M, Ruffoli R, Ferrucci M, Lazzeri G, Busceti CL, Pontarelli F, Battaglia G, et al. Parkinson-like syndrome induced by continuous MPTP infusion: convergent roles of the ubiquitin-proteasome system and alpha-synuclein. Proc Natl Acad Sci U S A. 2005;102:34138.

12. Robertson DC, Schmidt O, Ninkina N, Jones PA, Sharkey J, Buchman VL. Developmental loss and resistance to MPTP toxicity of dopaminergic neurones in substantia nigra pars compacta of gammasynuclein, alpha-synuclein and double alpha/gamma-synuclein null mutant mice. J Neurochem. 2004;89:1126-36.

13. Nakajo S, Shioda S, Nakai Y, Nakaya K. Localization of phosphoneuroprotein 14 (PNP 14) and its mRNA expression in rat brain determined by immunocytochemistry and in situ hybridization. Mol Brain Res. 1994;27:81-6.

14. Li JY, Henning Jensen P, Dahlstrom A. Differential localization of alpha-, beta- and gammasynucleins in the rat CNS. Neuroscience. 2002;113:463-78.

15. Malatynska E, Pinhasov A, Crooke J, Horowitz D, Brenneman DE, llyin SE. Levels of mRNA coding for alpha-, beta-, and gamma-synuclein in the brains of newborn, juvenile, and adult rats. J Mol Neurosci. 
2006;29:269-77.

16. da Costa CA, Masliah E, Checler F. Beta-synuclein displays an antiapoptotic p53-dependent phenotype and protects neurons from 6-hydroxydopamine-induced caspase 3 activation: cross-talk with alpha-synuclein and implication for Parkinson's disease. J Biol Chem. 2003;278:37330-5.

17. Windisch M, Hutter-Paier B, Rockenstein E, Hashimoto M, Mallory M, Masliah E. Development of a new treatment for Alzheimer's disease and Parkinson's disease using anti-aggregatory betasynuclein-derived peptides. J Mol Neurosci. 2002;19:63-9.

18. Windisch M, Hutter-Paier B, Schreiner E, Wronski R. Beta-Synuclein-derived peptides with neuroprotective activity: an alternative treatment of neurodegenerative disorders? J Mol Neurosci. 2004;24:155-65.

19. Hashimoto M, Rockenstein E, Mante M, Crews L, Bar-On P, Gage FH, Marr R, Masliah E. An antiaggregation gene therapy strategy for Lewy body disease utilizing beta-synuclein lentivirus in a transgenic model. Gene Ther. 2004;11:1713-23.

20. Hashimoto M, Rockenstein E, Mante M, Mallory M, Masliah E. beta-Synuclein inhibits alpha-synuclein aggregation: a possible role as an anti-parkinsonian factor. Neuron. 2001;32:213-23.

21. Fan Y, Limprasert P, Murray IV, Smith AC, Lee VM, Trojanowski JQ, Sopher BL, La Spada AR. Betasynuclein modulates alpha-synuclein neurotoxicity by reducing alpha-synuclein protein expression. Hum Mol Genet. 2006;15:3002-11.

22. Abeliovich A, Schmitz Y, Farinas I, Choi-Lundberg D, Ho WH, Castillo PE, Shinsky N, Verdugo JM, Armanini M, Ryan A, et al. Mice lacking alpha-synuclein display functional deficits in the nigrostriatal dopamine system. Neuron. 2000;25:239-52.

23. Chandra S, Fornai F, Kwon HB, Yazdani U, Atasoy D, Liu X, Hammer RE, Battaglia G, German DC, Castillo PE, Sudhof TC. Double-knockout mice for alpha- and beta-synucleins: effect on synaptic functions. Proc Natl Acad Sci U S A. 2004;101:14966-71.

24. Ninkina N, Papachroni K, Robertson DC, Schmidt O, Delaney L, O'Neill F, Court F, Rosenthal A, Fleetwood-Walker SM, Davies AM, Buchman VL. Neurons expressing the highest levels of gammasynuclein are unaffected by targeted inactivation of the gene. Mol Cell Biol. 2003;23:8233-45.

25. Anwar S, Peters O, Millership S, Ninkina N, Doig N, Connor-Robson N, Threlfell S, Kooner G, Deacon RM, Bannerman DM, et al. Functional Alterations to the Nigrostriatal System in Mice Lacking All Three Members of the Synuclein Family. J Neurosci. 2011;31:7264-74.

26. Al-Wandi A, Ninkina N, Millership S, Williamson SJ, Jones PA, Buchman VL. Absence of alphasynuclein affects dopamine metabolism and synaptic markers in the striatum of aging mice. Neurobiol Aging. 2010;31:796-804.

27. Ninkina N, Tarasova TV, Chaprov KD, Roman AY, Kukharsky MS, Kolik LG, Ovchinnikov R, Ustyugov $A A$, Durnev AD, Buchman VL. Alterations in the nigrostriatal system following conditional inactivation of alpha-synuclein in neurons of adult and aging mice. Neurobiol Aging. 2020;91:76-87.

28. Connor-Robson N, Peters OM, Millership S, Ninkina N, Buchman VL. Combinational losses of synucleins reveal their differential requirements for compensating age-dependent alterations in 
motor behavior and dopamine metabolism. Neurobiol Aging. 2016;46:107-12.

29. Ninkina N, Connor-Robson N, Ustyugov AA, Tarasova TV, Shelkovnikova TA, Buchman VL. A novel resource for studying function and dysfunction of alpha-synuclein: mouse lines for modulation of endogenous Snca gene expression. Sci Rep. 2015;5:16615.

30. Jakes R, Spillantini MG, Goedert M. Identification of two distinct synucleins from human brain. FEBS Lett. 1994;345:27-32.

31. Millership SJ, Da Silva Xavier G, Choudhury Al, Bertazzo S, Chabosseau P, Pedroni SM, Irvine EE, Montoya A, Faull P, Taylor WR, et al. Neuronatin regulates pancreatic beta cell insulin content and secretion. J Clin Invest. 2018;128:3369-81.

32. Gainetdinov RR, Fumagalli F, Jones SR, Caron MG. Dopamine transporter is required for in vivo MPTP neurotoxicity: evidence from mice lacking the transporter. J Neurochem. 1997;69:1322-5.

33. Miller GW, Gainetdinov RR, Levey Al, Caron MG. Dopamine transporters and neuronal injury. Trends Pharmacol Sci. 1999;20:424-9.

34. Senior SL, Ninkina N, Deacon R, Bannerman D, Buchman VL, Cragg SJ, Wade-Martins R. Increased striatal dopamine release and hyperdopaminergic-like behaviour in mice lacking both alphasynuclein and gamma-synuclein. Eur J Neurosci. 2008;27:947-57.

35. Davidson WS, Jonas A, Clayton DF, George JM. Stabilization of alpha-synuclein secondary structure upon binding to synthetic membranes. J Biol Chem. 1998;273:9443-9.

36. Middleton ER, Rhoades E. Effects of curvature and composition on alpha-synuclein binding to lipid vesicles. Biophys J. 2010;99:2279-88.

37. Westphal $\mathrm{CH}$, Chandra SS. Monomeric synucleins generate membrane curvature. J Biol Chem. 2013;288:1829-40.

38. Mosharov EV, Staal RG, Bove J, Prou D, Hananiya A, Markov D, Poulsen N, Larsen KE, Moore CM, Troyer MD, et al. Alpha-synuclein overexpression increases cytosolic catecholamine concentration. J Neurosci. 2006;26:9304-11.

39. Morciano M, Burre J, Corvey C, Karas M, Zimmermann H, Volknandt W. Immunoisolation of two synaptic vesicle pools from synaptosomes: a proteomics analysis. J Neurochem. 2005;95:1732-45.

40. Krantz DE, Peter D, Liu Y, Edwards RH. Phosphorylation of a vesicular monoamine transporter by casein kinase II. J Biol Chem. 1997;272:6752-9.

41. Holtje $M$, von Jagow B, Pahner I, Lautenschlager M, Hortnagl H, Nurnberg B, Jahn R, Ahnert-Hilger G. The neuronal monoamine transporter VMAT2 is regulated by the trimeric GTPase Go(2). J Neurosci. 2000;20:2131-41.

42. Requena DF, Parra LA, Baust TB, Quiroz M, Leak RK, Garcia-Olivares J, Torres GE. The molecular chaperone Hsc70 interacts with the vesicular monoamine transporter-2. J Neurochem. 2009;110:581-94.

43. Tsudzuki T, Tsujita M. Isoosmotic isolation of rat brain synaptic vesicles, some of which contain tyrosine hydroxylase. J Biochem. 2004;136:239-43. 
44. Cartier EA, Parra LA, Baust TB, Quiroz M, Salazar G, Faundez V, Egana L, Torres GE. A biochemical and functional protein complex involving dopamine synthesis and transport into synaptic vesicles. J Biol Chem. 2010;285:1957-66.

45. Dev KK, Hofele K, Barbieri S, Buchman VL, van der Putten H. Part II: alpha-synuclein and its molecular pathophysiological role in neurodegenerative disease. Neuropharmacology. 2003;45:14-44.

46. Sulzer D. Multiple hit hypotheses for dopamine neuron loss in Parkinson's disease. Trends Neurosci. 2007;30:244-50.

47. Venda LL, Cragg SJ, Buchman VL, Wade-Martins R. alpha-Synuclein and dopamine at the crossroads of Parkinson's disease. Trends Neurosci. 2010;33:559-68.

\section{Figures}




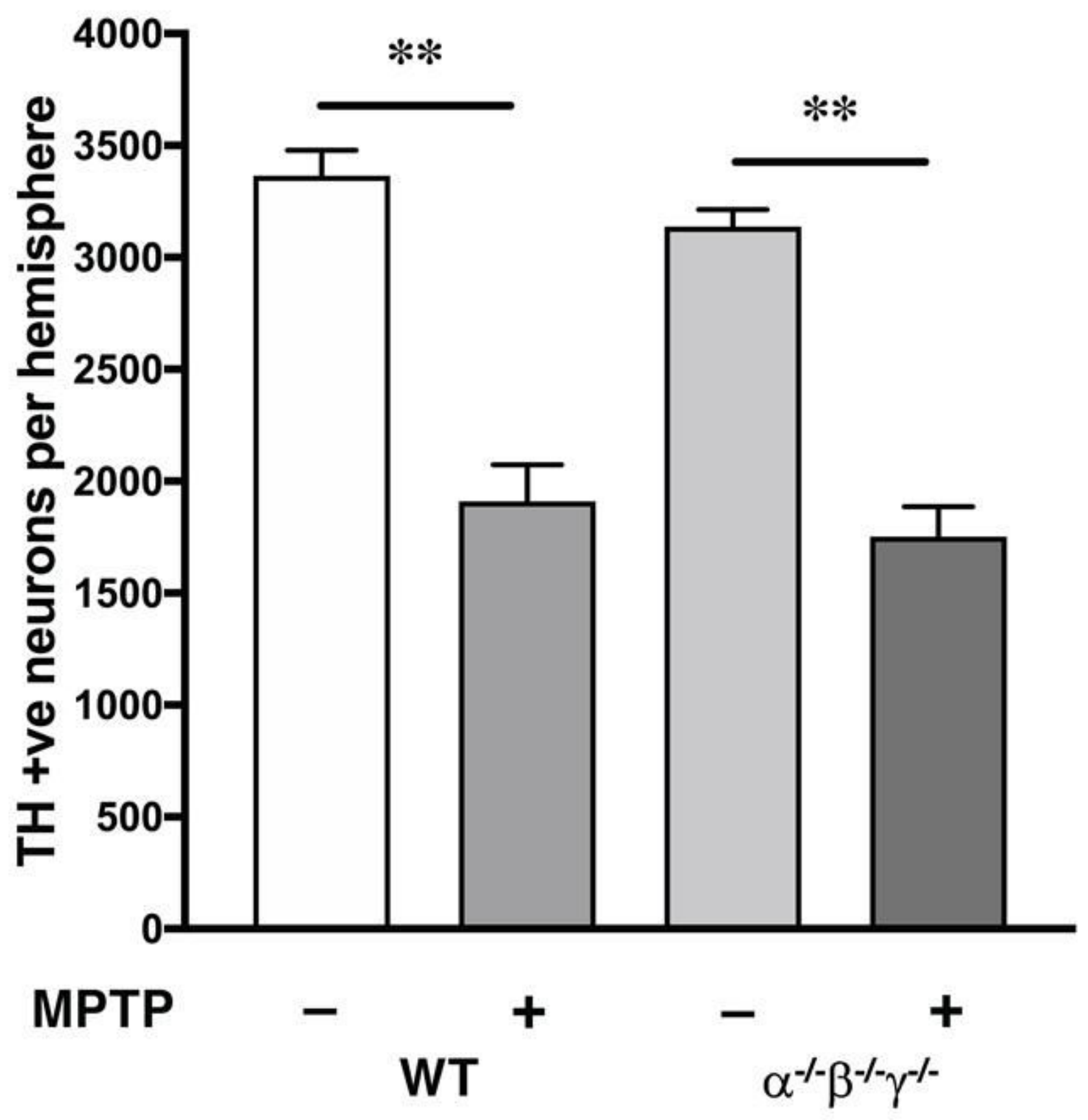

Figure 1

Sensitivity of SNpc dopaminergic neurons of wild type and triple synuclein deficient mice to subchronic MPTP treatment. Bar chart shows means \pm s.e.m. of total number of TH-positive neurons in the SNpc of

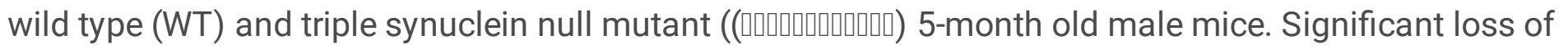
neurons was observed for both genotypes following MPTP treatment ( $* * p<0.0001$; one-way ANOVA with Sidak's multiple comparison test; $n=14-20$ per genotype/treatment). No difference in the degree of neuronal loss was found between genotypes ( $43.2 \pm 4.87 \%$ for WT mice and $44.1 \pm 4.26 \%$ for TKO mice). 
a

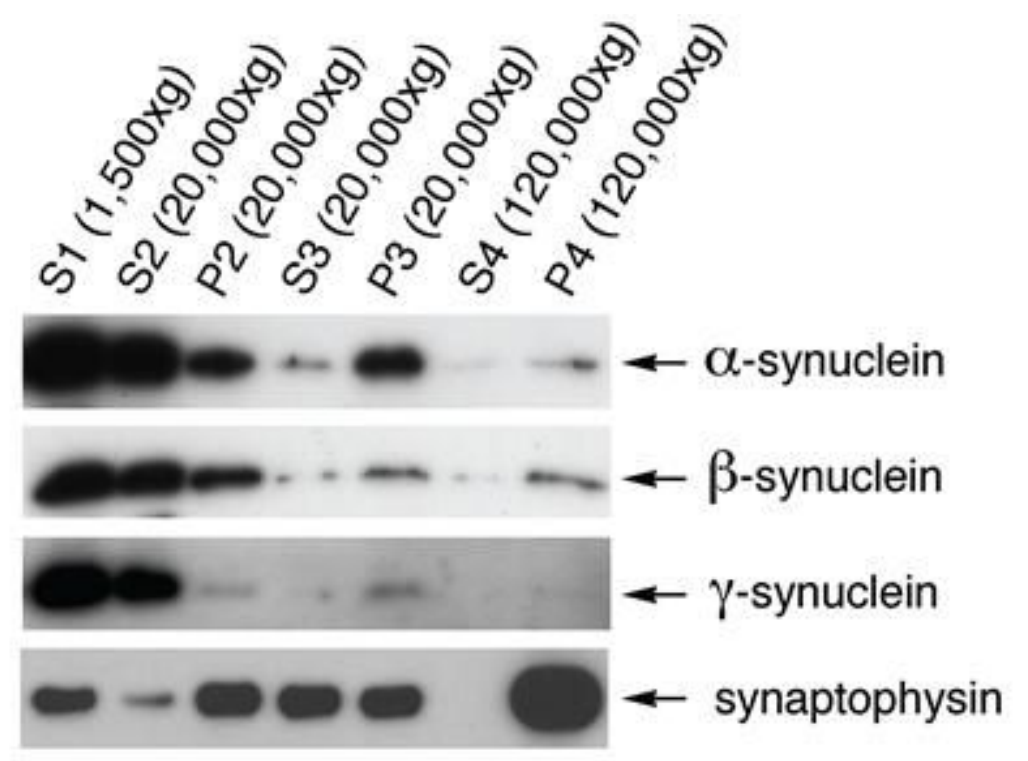

b

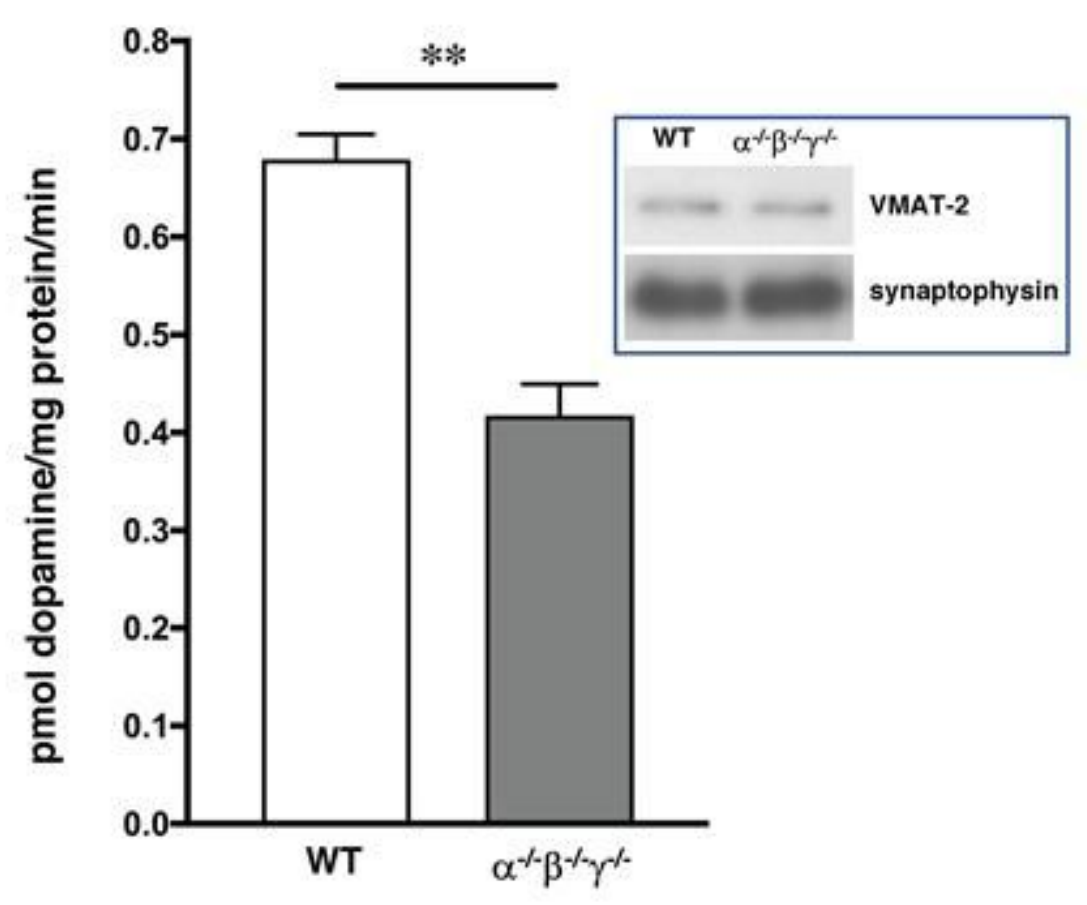

Figure 2

Synucleins are associated with striatal synaptic vesicles and affect dopamine uptake. (a) Western blot analysis of proteins in fractions of wild type mouse striatum. Post-nuclear supernatant (S1) was centrifuged at 20,000 x g, synaptosomes in the resulting pellet (P2) were lysed by homogenization in hypotonic buffer and again centrifuged at $20,000 \times \mathrm{g}$ to separate heavy synaptic membrane fraction (pellet P3) from cytosolic fraction containing small synaptic vesicle (supernatant S3). Synaptic vesicle fraction (P4) was obtained from the supernatant S3 by centrifugation at 120,000 x g. (b) Bar chart shows means \pm s.e.m. of dopamine uptake by synaptic vesicles isolated from the striatum of 5 -month old male wild type (WT) and TKO ( 
independent experiments). A representative Western blot in the inset illustrates equal amounts of VMAT-2 in vesicular fractions isolated from striata of wild type and TKO mice.
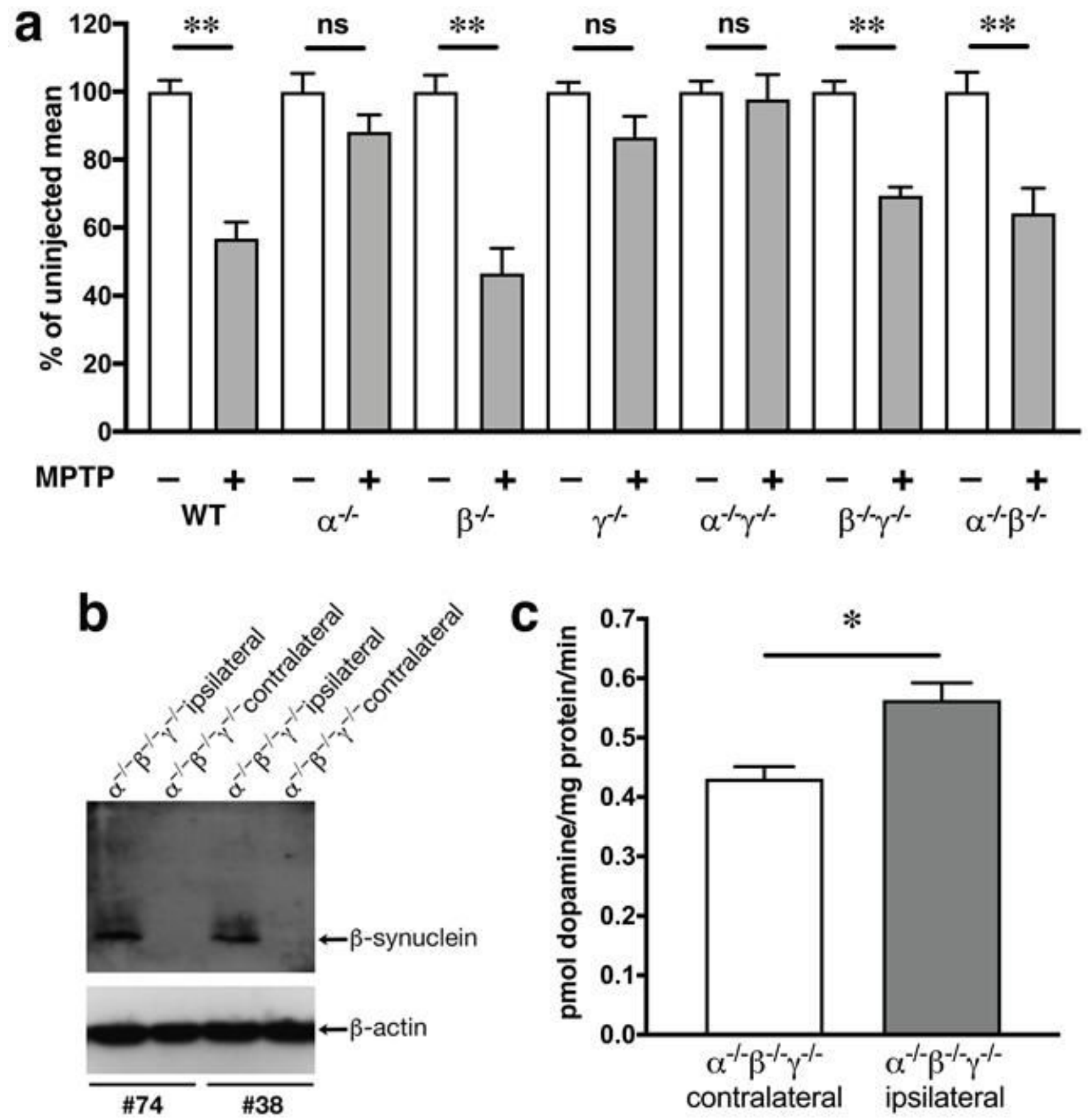

Figure 3

\-synuclein is pivotal for acquiring MPTP resistance by dopaminergic neurons lacking other synucleins and potentiates vesicular dopamine uptake in vivo. (a) Bar charts show means \pm s.e.m. of the number of TH-positive neurons in the SNpc of wild type (WT), single (

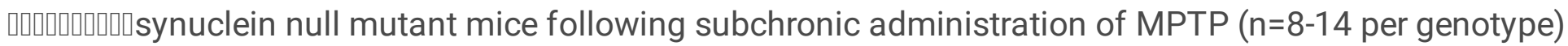
expressed as percent of the number of neurons in control vehicle-injected animals of the same genotype (**p $<0.0001$, one-way ANOVA with pairwise uncorrected Fisher's LSD test). (b, c) Analysis of dopamine uptake by synaptic vesicles from striata of TKO ( 


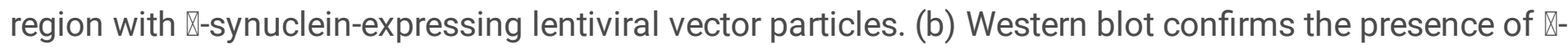
synuclein in the ipsilateral but not contralateral striatum of two injected TKO mice. (c) Bar chart shows means \pm s.e.m. of dopamine uptake by synaptic vesicles isolated from the ipsilateral and contralateral striatum of 6 TKO animals ( ${ }^{*} \mathrm{p}<0.0286$, Mann-Whitney U-test).

a

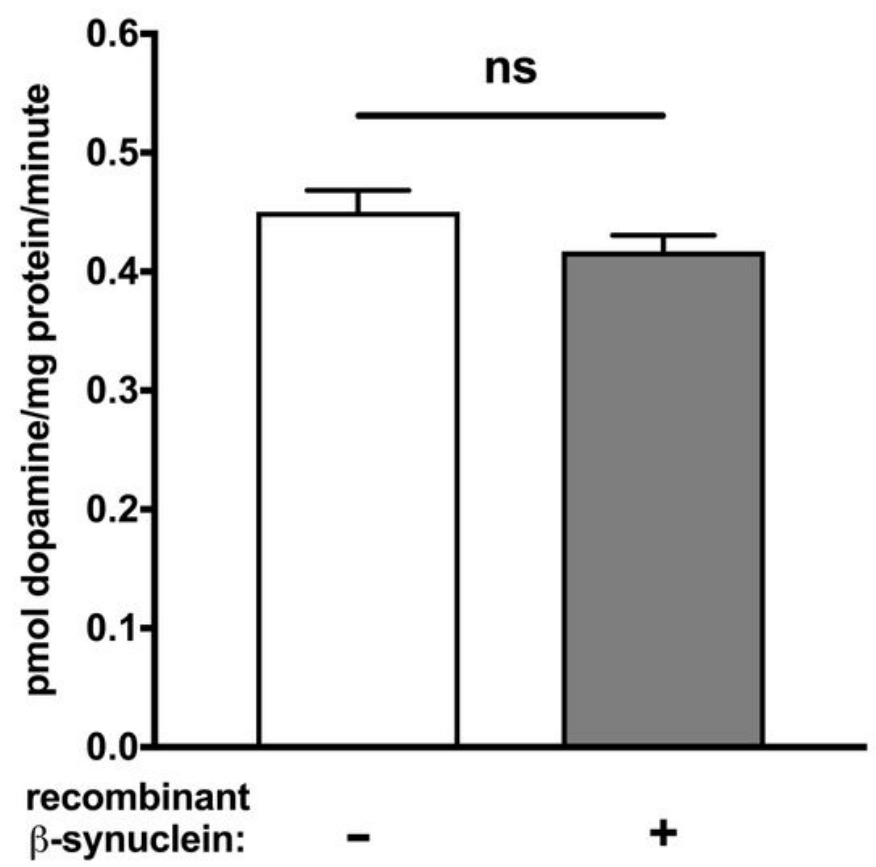

b

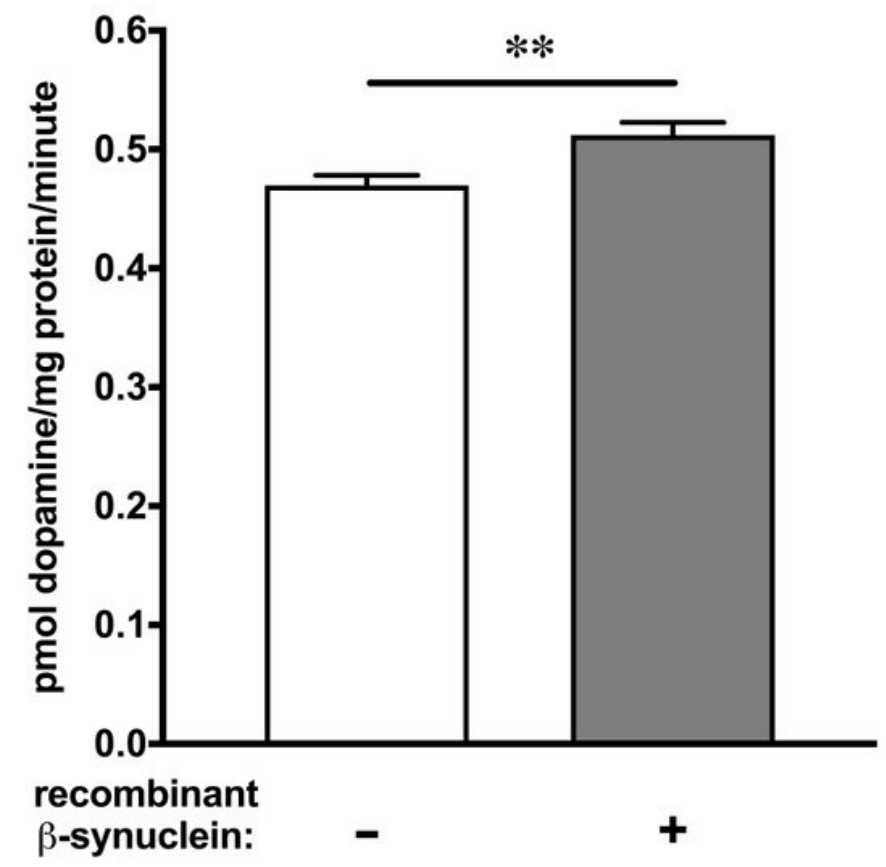

Figure 4

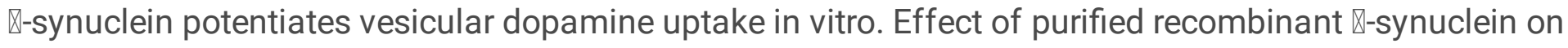
dopamine uptake by synaptic vesicles isolated from TKO mice. (a) Bar chart shows means \pm s.e.m. of dopamine uptake in the presence of purified recombinant $\triangle$-synuclein added to the uptake reaction mixture to a final concentration of $20 \mu \mathrm{g} / \mathrm{ml}$ ( $\mathrm{n}=7$ for each condition from two independent experiments, $\mathrm{ns}, \mathrm{p}=0.1807$, Mann-Whitney U-test). (b) Bar chart shows means \pm s.e.m. of dopamine uptake after

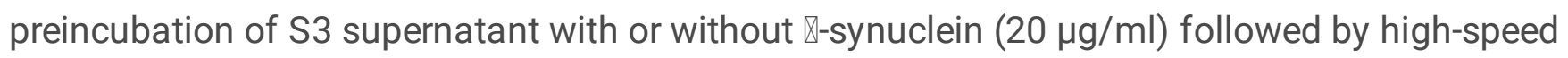
sedimentation of vesicles before use in the uptake reaction $(n=13$ for each conditions from three independent experiments, ${ }^{* *} \mathrm{p}<0.0035$, Mann-Whitney U-test). 


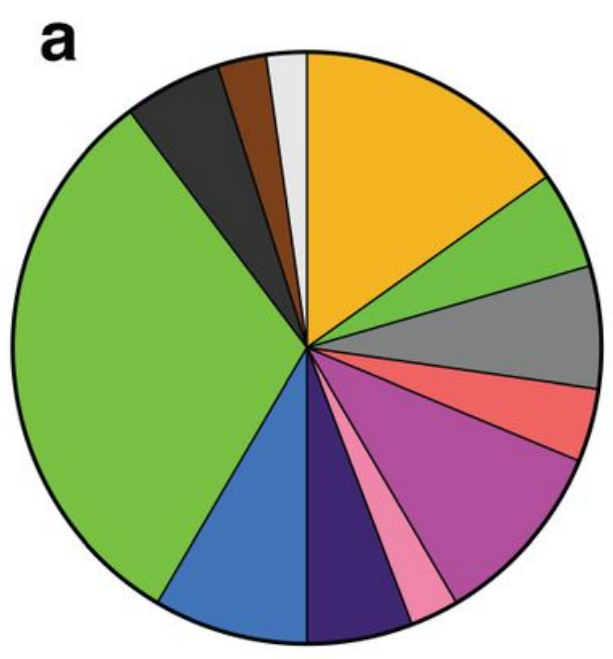

synaptic vesicles (34)

endosomes/lysosomes (12)

ER/Golgi/transport vesicles (15)

other vesicles (9)

plasma membrane (23)

other membranes (6)

mitochondria (13)

cytoskeleton (19)

cytoplasm (70)

nucleus (12)

extracellular (6)

undefined (5)

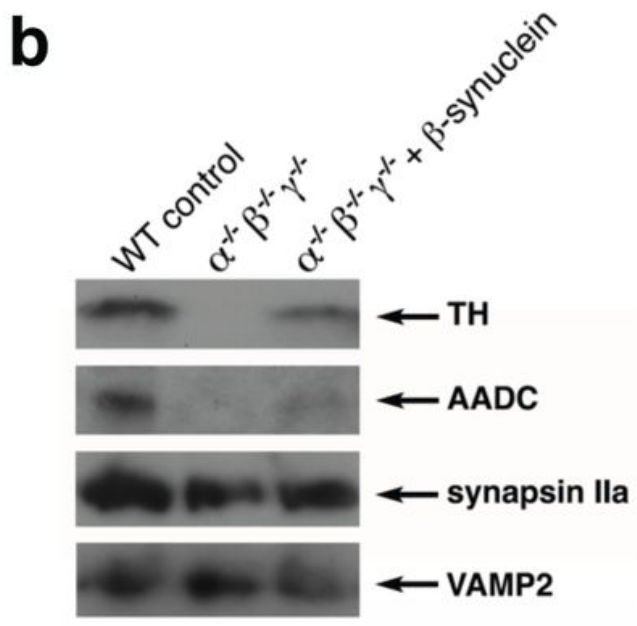

Figure 5

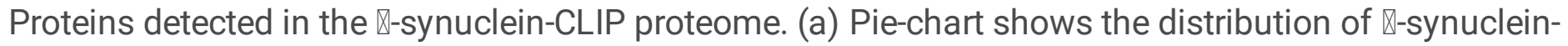
CLIP proteome proteins between cell compartments associated with their main compartmentalisation and/or function(s). The full list of these proteins can be found in Additional file 4. (b) Western blot analysis of proteins with principally vesicular (VAMP2 and synapsin Ila) or predominantly cytosolic (AADH and TH) localisation. Equal amounts of total proteins eluted from Tactin beads (see Methods section for details) were loaded on each lane. Proteins were obtained from striatal synaptic vesicles prepared by high-speed centrifugation (P4 fraction) of S3 fraction containing synaptic vesicles and cytosolic proteins of TKO mice. Prior to centrifugation S3 fraction proteins were cross-linked in the presence ( purified synaptic vesicles from the striata of wild type mice are loaded to the 'WT control' lane.

\section{Supplementary Files}

This is a list of supplementary files associated with this preprint. Click to download.

- Additionalfile4TableS1.xlsx

- Additionalfile3FigS3.pdf

- Additionalfile2Figs2.pdf

- Additionalfile1FigS1.pdf 